\title{
A institucionalização das políticas e da gestão ambiental no Brasil: avanços, obstáculos e contradições
}

\section{The Institutionalization of Environmental Policies and Management in Brazil: Advances, Obstacles and Contradictions}

\author{
Gustavo Ferreira da Costa LIMA*
}

\begin{abstract}
RESUMO
O trabalho propõe uma reflexão sobre o processo recente de institucionalização das políticas e da gestão ambiental no Brasil. Revisa a literatura da área a partir de referenciais da Ecologia Política que nas décadas finais do século XX emergiu como um novo campo de saber fundado na crítica e na politização dos problemas ambientais, a partir de uma reflexão sobre sua gênese, conseqüências, contradições e possíveis alternativas. Nessa discussão, articula os conceitos de política e gestão ambiental, sustentabilidade democrática e democracia participativa, além de outros menos centrais. Procura refletir sobre os avanços, obstáculos e contradições do processo citado e verificar se ele foi capaz de conter a degradação ambiental e instituir uma sustentabilidade democrática no país. O artigo constata que as políticas ambientais avançaram relativamente no Brasil, sobretudo, em aspectos legais e institucionais, em uma tendência à descentralização, na difusão da informação sobre os problemas ambientais no interior da sociedade e na construção da noção de desenvolvimento sustentável, como recurso discursivo na conciliação dos conflitos entre meio ambiente e desenvolvimento. Constituiu-se, por um lado, um sistema governamental de agências ambientais nos três níveis de governo e, por outro lado, um aparato jurídico amplo, reconhecido pelos especialistas como um dos mais avançados do mundo. Contudo, apesar desses avanços relativos, a análise conclui que as políticas ambientais no Brasil avançaram de um modo contraditório e vacilante e não foram capazes de superar a crescente degradação ambiental e os conflitos políticos e econômicos decorrentes da expansão capitalista no país.
\end{abstract}

Palavras-chave: política ambiental; gestão ambiental; sustentabilidade.

\begin{abstract}
This article discusses the recent institutionalization process of environmental policies and management in Brazil. It reviews bibliography from the perspective of Political Ecology, that emerged at the end of twentieth century as a new field of knowledge founded in the critic and politicizing of environmental problems since a reflection of its genesis, consequences, contradictions and possible alternatives. This
\end{abstract}

\footnotetext{
" Doutor em Ciências Sociais pela UNICAMP, professor e pesquisador do Departamento de Ciências Sociais - DCS e do Programa Regional de Pós-Graduação em Desenvolvimento e Meio Ambiente - PRODEMA. Universidade Federal da Paraíba - UFPB. Email: gust3lima@uol.com.br
} 
discussion articulates the concepts of environmental policy, environmental management, democratic sustainability, and participatory democracy, besides other issues of less centrality. It discusses environmental policies advancements, obstacles and contradictions, as well as tries to verify if these policies were capable of restraining environmental degradation and to establish a democratic sustainability in the country. The article certifies that environmental policies advanced to a certain degree in Brazil, especially in legal and institutional aspects, in a tendency to decentralization, in the diffusion of information about environmental problems, and in the construction of sustainable development notion as a discursive resource in conciliating conflicts between environment and development. On the one hand, a governmental system of environmental agencies in all levels of government administration has been constituted. On the other hand, a broad judicial array, recognized by experts as one of the most advanced in the world, has also been established. However, in spite of these relative advances, the analysis concludes that environmental policies in Brazil advanced in a hesitant and contradictory way that made them incapable to overcome environmental degradation and political conflicts resulting from capitalist expansion in the country.

Key-words: environmental policy; environmental management; sustainability.

\section{Introdução}

O presente trabalho propõe uma reflexão sobre o processo recente de institucionalização das políticas e da gestão ambiental no Brasil. Revisa a literatura dessa temática a partir de referenciais da Ecologia Política. A Ecologia Política emergiu como um campo de saber nas décadas finais do século XX, a partir da crítica e da politização dos problemas ambientais, de sua gênese, consequências, contradições e possíveis alternativas. Nesse sentido, trouxe a contribuição crítica das ciências humanas e sociais para a reflexão e para o debate ecológico, até então pautado por leituras biologicistas e despolitizadas dos problemas ambientais. Procura, por um lado, incorporar ao debate ambiental aqueles elementos que os olhares disciplinares das ciências naturais deixavam fora da análise, como a influência sobre o meio ambiente dos modelos de desenvolvimento econômico-social; os interesses e conflitos das classes sociais; os padrões culturais e ideológicos hegemônicos e as injunções políticas dominantes em cada contexto histórico-social. Agrega, em sentido complementar, a consciência de uma ecoesfera dinâmica, que contém limites biofísicos e que impõe restrições sobre a ordem econômica e social, embora essas restrições nem sempre sejam percebidas ou consideradas pelos cientistas sociais. Essa abordagem política das questões ambientais se notabilizou pelas contribuições de pensadores como André Gorz, Jean Pierre Dupuy, Cornelius Castoriadis, Herbert Marcuse, Serge Moscovici e Edgar Morin, entre outros, mas se estendeu amplamente pelas gerações seguintes, inspirando diversos autores contemporâneos nacionais e internacionais com os quais aqui dialogamos (ALPHANDÈRY; DUPONT, 1992; LIPIETZ, 2000; LOUREIRO, 2003).

Nessa discussão, articulam-se os conceitos de política e gestão ambiental, sustentabilidade democrática e democracia participativa, além de outros menos centrais. Busca-se, nesse sentido, refletir sobre os avanços, obstáculos e contradições do processo citado e verificar em que medida ele foi capaz de conter a degradação ambiental e instituir uma sustentabilidade democrática no país nas décadas recentes.

Para fins objetivos, recorrer-se-á ao conceito de política ambiental veiculado por Barbieri (2006), que a define como o conjunto de diretrizes, objetivos e instrumentos de ação que o poder público utiliza para produzir efeitos desejáveis sobre o meio ambiente. Quanto ao conceito de gestão ambiental, será usada a formulação de Quintas (2006, p. 30): "Gestão ambiental, portanto, é vista aqui como o processo de mediação de interesses e conflitos (potenciais ou explícitos) entre atores sociais que agem sobre os meios físico-natural e construído, objetivando garantir o direito ao meio ambiente ecologicamente equilibrado, conforme determina a Constituição Federal".

A análise realizada permite constatar que as políticas ambientais avançaram relativamente, sobretudo, em aspectos legais e institucionais, em uma tendência à descentralização; na difusão da informação sobre os problemas ambientais no interior da sociedade e na construção da noção de desenvolvimento sustentável como recurso discursivo e político de conciliação dos conflitos entre meio ambiente e desenvolvimento. Ou seja, do início da década de 1970 até os dias atuais, observou-se um processo 
crescente e contínuo de institucionalização de políticas e de práticas de gestão ambiental manifesto na criação de agências ambientais governamentais, no marco legal que normatiza a gestão dos problemas ambientais no país, no debate teórico-político que fundamenta e legitima a regulação da questão ambiental e na difusão de informações sobre a crise ambiental.

Nesse sentido, é inegável que se experimentaram avanços, mas a análise demonstra que esse processo de institucionalização ocorreu de modo contraditório e permeado por um conjunto de obstáculos que não o tornou capaz de superar a crescente degradação ambiental e os conflitos políticos e econômicos decorrentes da expansão capitalista no país. Ou seja, os avanços conquistados não consolidaram uma sustentabilidade democrática que garantisse qualidade de vida digna à maioria da população e direito de participar das decisões políticas que governam a gestão do patrimônio ambiental público, preconizado pela Constituição de 1988. Nesse sentido, cabe indagar: que problemas e obstáculos impediram ou dificultaram as políticas e os instrumentos de gestão formulados de atingir os objetivos a que se destinavam? Quando a sustentabilidade democrática é evocada supõe-se que a própria ambiguidade do debate sobre a sustentabilidade permite que ela possa também ser construída com outros sentidos e de outras maneiras - autoritárias, reducionistas, elitistas ou mercantis, por exemplo.

O debate que problematiza a efetividade das políticas ambientais no país, embora não seja de todo consensual, permite diagnosticar um conjunto de problemas que envolvem: a ausência histórica de prioridade política da questão ambiental no Brasil; o nítido descompasso entre a existência de um corpo legal avançado e a frágil implementação prática dessas leis; a falta de integração e de coordenação entre as políticas setoriais que impactam o meio ambiente, como as políticas relacionadas à energia, aos transportes, à agropecuária, ao extrativismo, à industrialização e à mineração; a própria ambiguidade da ação do Estado que, por um lado, estimula e promove o crescimento econômico e a degradação dos recursos naturais e, por outro lado, tenta administrar o controle da degradação produzida; a redução da capacidade reguladora do Estado, que se intensificou com a crise econômica dos anos 1980 e 1990 e com o avanço das políticas neoliberais e que resultou em cortes orçamentários, de pessoal e de recursos técnicos e a emergência, no mesmo período, de discursos e conceitos de gestão ligados à lógica privada, como é o caso das noções de responsabilidade social, autorregulação, ecoeficiência, governança, parcerias, formação de consenso, mecanismos de desenvolvimento limpo, consumo e mercados verdes, ISO 14000 etc. (ACSELRAD, 2001, 2009; DUPAS, 2008; CAMARGO et al., 2004; LITTLE, 2003; CUNHA; COELHO, 2008).

Esse é o cerne do debate que será sistematizado e discutido no presente artigo, em diálogo com os aportes teóricos acima mencionados. Para tanto, a reflexão será desenvolvida em três momentos principais: o primeiro dedica-se a compreender a dinâmica da relação entre o Estado, a sociedade e o mercado no que diz respeito à gestão dos problemas ambientais; o segundo aborda os avanços experimentados na institucionalização das políticas e da gestão ambientais no país nas últimas décadas; o terceiro momento procura identificar os obstáculos e contradições que caracterizam esse processo e que impedem ou dificultam a plena realização de seus objetivos.

\section{Como o Estado, a sociedade e o mercado se relacionam no processo de gestão do meio ambiente}

A gestão ambiental moderna no Brasil iniciou-se na década de 1970 como resposta a uma crise ambiental sistêmica de grandes proporções que atingia todos os países, embora com ênfase especial nos países industrializados. Foram diversas as razões que despertaram a consciência da comunidade internacional para esse fato, entre os quais os próprios obstáculos à reprodução do sistema econômico, via encarecimento ou escassez de energia e matérias-primas essenciais; a geração de poluição de variados tipos com comprometimentos extensos sobre a qualidade da vida humana; os efeitos dos problemas e acidentes ambientais globais com riscos de grande magnitude e a ameaça ou o desaparecimento de espécies animais e vegetais. A ideia de uma crise ambiental sistêmica relaciona, por um lado, a multidimensionalidade dos problemas ambientais contemporâneos e, por outro lado, o alcance global de sua ocorrência. Significa dizer que a crise ambiental associa causas e produz efeitos plurais que transcendem a dimensão ecológica em sentido estrito, produzindo relações que se originam e impactam a economia, a cultura, a sociedade e a política e não mais se restringem à esfera local, mas atravessam todos os níveis territoriais, constituindo uma crise planetária.

As conferências internacionais promovidas pela ONU, a partir da Conferência de Estocolmo em 1972, e a 
ação dos movimentos ambientalistas internos induziram o governo brasileiro a instituir gradualmente um sistema de agências ambientais, fazendo do Estado o agente protagonista da formulação e implementação de políticas e de práticas de gestão ambiental no país.

Com a crise econômica mundial, o avanço do ideário neoliberal, a emergência de novos movimentos sociais e os resultados da Assembleia Nacional Constituinte, processados ao longo das décadas de 1980 e 1990, reduz-se a capacidade sistêmica de regulação do Estado, dando margem a novas propostas e práticas de descentralização política e a parcerias crescentes com organizações não governamentais e com o setor produtivo que, no plano discursivo e conceitual, vão se expressar nas noções de gestão compartilhada, de governança e de responsabilidade social, entre tantos outros novos termos. A crise econômica manifesta através da crise fiscal do Estado, a partir dos anos 1980, de déficits no balanço de pagamentos e de aumento do endividamento público, se refletiu na retração de investimentos governamentais e na reorientação das prioridades sociais, afetando negativamente a política salarial e as políticas públicas sociais e ambientais, atingidas por restrições orçamentárias, de recursos humanos e técnicos e de meios para implementar pesquisas, controle e fiscalização dos bens ambientais. Por outro lado, o próprio contexto de crise econômica e de endividamento incentivou estratégias produtivas de exportação que tendiam a impactar negativamente o ambiente, como é o caso da mineração, da pecuária extensiva e da agricultura de exportação, através de gêneros como soja, laranja, café, açúcar, álcool e milho, entre outros produtos. O avanço neoliberal, por seu turno, tanto estimulou a expansão do setor privado e dos negócios, através de iniciativas privatizantes; quanto operou no sentido de restringir a ação e o alcance da intervenção do Estado nos planos político, econômico e ideológico. Ideológica e discursivamente, tratava-se de desacreditar o potencial regulador da administração pública e de simultaneamente estimular a substituição desse papel do Estado por alternativas e iniciativas privadas de gestão, seja sob a forma de privatizações e/ou parcerias com organizações do terceiro setor, seja em associações público-privadas com grupos empresariais. A Constituinte de 1988, inspirada pelos novos movimentos sociais e pelo debate sobre os limites da centralização administrativa e da democracia representativa, adotou recomendações descentralizantes e participativas que serão tratadas adiante. Para Lüchmann (2002), a democracia participativa é um processo político que incorpora a participação da sociedade civil na regulação da vida coletiva. Um conceito baseado na ideia de que a legitimidade das decisões políticas deriva da deliberação pública de coletividades de cidadãos livres e iguais, que se contrapõe aos modelos elitistas, onde a política é dominada por um ou vários grupos que concentram o poder no interior da sociedade e cuja legitimidade deriva apenas do processo eleitoral.

\section{Os avanços na institucionalização das políticas ambientais no Brasil}

Como posto acima, após a Conferência de Estocolmo em 1972, o processo de institucionalização de políticas e da gestão ambiental no Brasil experimentou avanços consideráveis, sobretudo nos aspectos institucionais e legais, na tendência à descentralização política no sentido do deslocamento de atribuições e de poderes para os níveis estaduais e municipais e também no sentido do compartilhamento de aspectos da gestão ambiental com entidades da sociedade civil e do setor privado e, por último, na construção e no fortalecimento da noção de desenvolvimento sustentável como recurso político na negociação dos conflitos que emergem da articulação entre o desenvolvimento e o ambiente.

Assistiu-se, assim, à constituição gradual de um sistema governamental de agências ambientais que se institucionalizou gradualmente através da criação da Secretaria Especial de Meio Ambiente - SEMA, em 1973; do Instituto Brasileiro do Meio Ambiente e dos Recursos Naturais Renováveis - IBAMA, em 1989; do Ministério do Meio Ambiente, em 1993; da Agência Nacional de Águas - ANA, em 2001, e do Instituto Chico Mendes de Conservação da Biodiversidade - ICMBio, em 2007, entre tantas outras iniciativas estruturadoras do setor público ambiental. Ao lado dessa estrutura institucional, construiu-se igualmente um aparato jurídico amplo que compreende, entre outros, a Política Nacional de Meio Ambiente, de 1981, que deu origem ao Conselho Nacional de Meio Ambiente - CONAMA - e ao Sistema Nacional de Meio Ambiente - SISNAMA; a Política Nacional de Recursos Hídricos, de 1997, a Lei de Crimes Ambientais de 1998, a Política Nacional de Educação Ambiental - PNEA, de 1999, a Lei do Sistema Nacional de Unidades de Conservação - SNUC, de 2000, o Estatuto das Cidades, de 2001, e a recente Lei de Resíduos Sólidos, sancionada em 2010.

Com relação à descentralização da gestão ambiental, a literatura testemunha uma tendência crescente nessa di- 
reção, a partir de iniciativas como a Política Nacional de Meio Ambiente - PNMA, de 1981, e os mecanismos de gestão participativa instituídos pelo Conselho Nacional de Meio Ambiente-CONAMA; o capítulo de meio ambiente criado pela Constituinte de 1988, que introduziu princípios descentralizantes e democráticos de gestão; a ação de movimentos sociais e organizações não governamentais, fortalecidos na trajetória da redemocratização brasileira e, como ressaltou-se acima, pelos efeitos restritivos da crise econômica e do avanço neoliberal, ambos atuando como fatores fragilizadores da ação estatal que incentivavam a privatização e/ou minimização do papel do Estado (CARVALHO, 2005; CUNHA; COELHO, 2008, MAGLIO, 2000; SCARDUA, 2003).

A construção da noção de desenvolvimento sustentável foi outro elemento inovador no cenário das políticas ambientais, por possibilitar novas formas de conceber políticas e estratégias de gestão ambientais antes despercebidas. Isso porque, no momento que a antecedeu, os conflitos entre desenvolvimento e meio ambiente eram abordados por uma perspectiva de antagonismo e excludência que inviabilizava a negociação e/ou superação dos problemas atendendo simultaneamente às necessidades sociais e ambientais. De acordo com as opções colocadas à época, ou bem se desenvolvia a economia ou bem se preservava o ambiente. O discurso do desenvolvimento sustentável, por esse viés, embora envolto em controvérsias, introduziu a ideia de indissociabilidade entre o desenvolvimento e o ambiente e a possibilidade e formular novos modelos de desenvolvimento capazes de incluir a problemática ambiental. O debate sobre o desenvolvimento sustentável também inovou ao inserir a questão ambiental no núcleo de prioridades políticas da agenda internacional e ao abordar o desenvolvimento por uma nova perspectiva pluridimensional e de longo prazo que, ao menos em tese, se esforçava em superar os reducionismos econômicos e técnicos que o caracterizaram no período entre o pós-II Guerra e a crise econômica mundial iniciada em meados da década de 1970. Como se vê, o discurso do desenvolvimento sustentável trouxe inovações, embora persistam questionamentos sobre as ambiguidades e contradições expressas entre uma retórica idealizada e o contexto de uma economia hegemonizada pelo mercado, assunto que será discutido adiante (LIMA, 2003; DIEGUES, 1992; PORTO-GONÇALVES, 2004).

Portanto, as quatro décadas que sucederam os anos 1970, marco referencial da crise e da institucionalização de políticas ambientais no país, revelam uma trajetória de construção e fortalecimento gradual da gestão ambiental no Brasil, sobretudo, a partir do protagonismo do Estado, embora com a participação relativa do restante da sociedade organizada. Essa constatação, contudo, precisa ser avaliada e qualificada para que se torne possível a compreensão de como se deu esse processo de institucionalização, que características ele assumiu e em que medida ele foi capaz de conter a degradação ambiental produzida pela sociedade brasileira em sua inserção no contexto mundial. Essa é a reflexão que desenvolver-se-á a seguir.

\section{Limites e contradições das políticas ambientais no Brasil}

Como observou-se acima, a despeito do avanço das políticas e da gestão ambiental no país, ainda não atingiu-se um desempenho suficientemente democrático, eficiente e complexo que possa ser considerado sustentável em um sentido amplo. Uma avaliação pontual das políticas ambientais no Brasil pode até indicar um ou outro setor específico que tenha obtido bons resultados ao longo dos últimos anos, como é o caso da matriz energética brasileira em relação à de outros países mais dependentes de combustíveis fósseis, entre outras especificidades. Uma análise em perspectiva sistêmica, ao contrário, vai constatar a precariedade dos indicadores de preservação ambiental no país.

Apenas a título de ilustração, é possível considerar os resultados da avaliação realizada para o período 1992 2002 pela parceria entre a Fundação Getúlio Vargas - FGV - e o Instituto Socioambiental - ISA - publicada no livro Meio ambiente Brasil: avanços e obstáculos pós-Rio-92 (CAMARGO et al., 2004). Nesse trabalho, são reunidos indicadores gerais sobre áreas como: biodiversidade e biomas, agricultura, meio ambiente urbano, recursos hídricos, energia, responsabilidade social das empresas, padrões de consumo e produção, participação da sociedade civil, evolução da consciência ambiental da população, governança, meios de implementação e informação. Dessa avaliação, o relatório destaca, em um sentido geral, que "apesar de alguns avanços localizados e importantes, não se alcançou o patamar de políticas afirmativas que pudessem contribuir para reverter os altos níveis de pobreza, de devastação ambiental ou de fragilidade dos poderes públicos, responsáveis pelo controle e fiscalização das ações de degradação ambiental no país" (CAMARGO et al., 2004, p. 29-30). Mais adiante, o mesmo trabalho reafirma que a avaliação 
do conjunto de indicadores acima mencionados revela que "os problemas seguem sem solução e, em muitos casos, se agravaram" (CAMARGO et al., 2004, p. 30).

Trata-se, portanto, de indagar por que os objetivos e as metas das políticas ambientais não foram atingidos? Que problemas e obstáculos impediram ou dificultaram a concretização dessas finalidades? Esses são alguns dos questionamentos que orientam a presente reflexão.

A revisão da literatura sobre o tema permite desenhar um esboço de diagnóstico dos limites das políticas ambientais, apontando os principais obstáculos que merecem ser discutidos.

Aparece em primeiro lugar a falta histórica de prioridade política da questão ambiental no Brasil. A questão ambiental nunca foi e continua não sendo uma prioridade política no país (MONOSOWSKI, 1989; PÁDUA, 1991; ACSELRAD, 2001; TAVOLARO, 1999; FERREIRA, 1998; BERNARDO, 2001). Pádua (1991), em perspectiva histórica, mostra como a empresa colonial europeia se relacionava com o ambiente, ao batizar o território brasileiro descoberto sob o signo da devastação, empresa que se alongaria pelos séculos seguintes, através do império e da república, nos longos ciclos de exploração natural, econômica e social. No século XX, a posição brasileira na Conferência de Estocolmo de 1972, de defesa do crescimento econômico e de rejeição de quaisquer iniciativas políticas de conservação que sacrificassem esse crescimento, atesta qual era a prioridade das elites políticas e econômicas no comando (MAIMON, 1992; DIAS, 1993). Esse descaso histórico com o patrimônio ambiental do país ${ }^{1}$ acompanha, com algumas variações político-ideológicas, os sucessivos planos econômicos dos governos Vargas, Kubitschek, Goulart, os que fizeram o ciclo autoritário de 1964 a 1985 até os dias atuais, onde assistimos aos conflitos dos projetos desenvolvimentistas do Plano de Aceleração do Crescimento - PAC - do segundo governo Lula da Silva com as agências de licenciamento e os movimentos ambientais, planos reafirmados no programa da presidenta eleita na última eleição de 2010. Bergamini (2010), analisando a distribuição orçamentária da União para o período 20032010, que compreende as duas gestões Lula da Silva, mostra que o Ministério do Meio Ambiente - MMA - recebeu da União, nesse período, $\mathrm{R} \$ 9,8$ bilhões contra $\mathrm{R} \$ 51,9$ bilhões destinados ao Ministério da Agricultura, R\$296, 5 bilhões ao Ministério da Defesa, $\mathrm{R} \$ 343,8$ bilhões ao Ministério da Saúde, R \$ 205,6 bilhões ao Poder Judiciário, R \$ 1.619,1 bilhões aos serviços da dívida e R \$ 2.843,8 bilhões para renegociação da dívida. Ou seja, para todos os efeitos, o MMA está entre os últimos itens de despesa da União, só ficando atrás dos Ministérios da Cultura, dos Esportes e do Turismo. A constatação desta rápida análise das prioridades políticas governamentais no Brasil é de que as políticas, os planos, programas e projetos de crescimento e/ou desenvolvimento econômico sempre foram as prioridades incontestes em qualquer cenário histórico que se considere. É possível se pensar que essa constatação não ocorra apenas no Brasil e que em muitos poucos países a questão ambiental seja um tema prioritário. Vivemos sem dúvida em um mundo economicizado, mas, nas quatro décadas que nos separam dos primeiros alertas das ameaças ambientais, muitas iniciativas políticas, econômicas e socioeducacionais foram tomadas globalmente para corrigir as graves distorções verificadas e, embora esse seja ainda um processo aberto e em construção, os resultados positivos já despontam nos países e sociedades que levaram a sério o problema e empreenderam reformas para minimizar ou resolver os problemas existentes, como demonstram as experiências ambientais exitosas da Suécia e da Costa Rica, exemplos de casos emblemáticos. No caso brasileiro, mesmo quando se considera a relativa limitação do orçamento público, nada justifica, por exemplo, os níveis atuais e persistentes de desmatamento; os baixíssimos níveis de saneamento básico e de qualidade da água distribuída em significativas frações do território nacional; o padrão de urbanidade de nossas metrópoles; o descaso com a qualidade de nossa educação, incluída a educação ambiental; a precária gestão dos resíduos sólidos, os volumes de agrotóxicos consumidos, a devastação impune produzida pelo agronegócio e a baixa eficiência das políticas de controle e fiscalização, apenas para mencionar os problemas mais evidentes.

Outro obstáculo consensual ao avanço das políticas é o descompasso patente entre as leis e os discursos avançados, formulados e difundidos no universo institucional da gestão ambiental e seu escasso cumprimento. Leis reconhecidamente importantes não são aplicadas devido a conflitos de interesses de grupos e/ou setores econômicos e políticos; à falta de vontade política governamental; à dissociação entre os objetivos das políticas ambientais e as Pádua (1987, 2002), entre outros historiadores ambientais, constata a existência de um pensamento e uma crítica ambiental ao longo da história do Brasil, embora
essa crítica nunca tenha se convertido em uma expressão política hegemônica no país. 
estratégias de desenvolvimento adotadas; à cultura política disseminada - clientelismo, patrimonialismo - que invade o cotidiano e as instituições públicas envolvidas com a regulação ambiental e à carência de recursos e/ou debilidade dos órgãos responsáveis por sua aplicação (FERREIRA, 1998; MONOSOWSKI, 1989; TAVOLARO, 1999).

O terceiro limite estrutural das políticas e da gestão ambiental no Brasil é a falta de integração e coordenação de políticas setoriais que impactam o ambiente, como é o caso das políticas de energia, de agricultura, de transportes, de ciência e tecnologia, de indústria e mineração, entre outras. Ou seja, não há um planejamento e uma ação integrada entre as diversas instâncias de governo ou mesmo externas ao governo que, direta ou indiretamente, afetam o meio ambiente natural ou construído (BERNARDO, 2001; MONOSOWSKI, 1989; ACSELRAD, 2001). Em uma política de desenvolvimento consequente, a questão ambiental deveria ser abordada tanto transversal quanto integradamente para garantir que as ações deflagradas em diferentes pontos do sistema se comunicassem e se complementassem mutuamente, previssem e prevenissem as consequências e deseconomias de umas sobre as outras, as descontinuidades administrativas e poupassem as duplicidades eventualmente existentes. Neste ponto, se insere a relevância do pensamento complexo face à multidimensionalidade e à imprevisibilidade dos problemas e riscos contemporâneos. As práticas políticas e modelos de gestão reducionistas e centralizadores adotados demonstram ser cada vez mais ineficientes ante os novos desafios sociais e ambientais (MORIN, 1996). Os episódios de chuvas intensas e enchentes de graves consequências que, infelizmente, tornaram-se rotineiros nos cenários urbanos brasileiros, são exemplos típicos da ausência e/ou baixa qualidade das políticas públicas urbanas, ambientais e de defesa civil.

A ambiguidade do papel do Estado em relação aos problemas ambientais é outro elemento que cria dificuldades adicionais ao avanço das políticas para o setor. Ou seja, a ação global do Estado ao estimular o crescimento econômico sob diferentes formas produz, inevitavelmente, uma ampla diversidade de impactos ambientais negativos que são transferidos para toda a sociedade, ainda que assimetricamente. Por outro lado, cabe a esse mesmo Estado fazer a regulação, o controle e a gestão ambiental para garantir a própria reprodução dos sistemas econômico, político e social, gerenciar os conflitos de interesses entre grupos concorrentes e responder às demandas dos movimentos sociais como tarefas de legitimação da ordem constituída.
Hannigan (2009), ao apresentar o pensamento de Schnaiberg, explora essa tensão dialética das sociedades industriais avançadas através do conflito entre os objetivos de acumulação de capital e as demandas de proteção ambiental, onde o Estado, como agente mediador, é desafiado a intervir para atender a essas duas orientações contraditórias. Segundo ele:

Presos numa posição contraditória, pois ambos, promotor do desenvolvimento econômico e regulador ambiental, engajam os governos em um processo de "gestão ambiental" no qual eles tentam legislar um limitado grau de proteção suficiente para evitar crítica, mas não significativamente o suficiente para descarrilar a locomotiva do crescimento. Ao legislar leis ambientais e procedimentos que são complexos, ambíguos e abertos à exploração pelas forças da produção de capital e da acumulação, o Estado reafirma seu compromisso com estratégias de promoção do desenvolvimento econômico (HANNIGAN, 2009, p. 41).

As reflexões de Poulantzas (1973) sobre o Estado moderno também são úteis à compreensão dessa ambiguidade do papel do Estado em relação aos problemas ambientais. Ressalta, nesse sentido, a noção de autonomia relativa do Estado em relação à classe economicamente dominante que, por sua vez, decorre da não coincidência no capitalismo entre as classes dominantes e a burocracia estatal; da constatação da existência e disputa de uma pluralidade de elites; das pressões das classes subordinadas e dos conflitos e divergências que emergem dessas relações contraditórias. Essa rede complexa de relações obriga o Estado, como mediador sistêmico, a assumir um comportamento pendular e relativamente flexível, que garanta a reprodução do sistema social enquanto totalidade, embora essa autonomia tenha limites - que são os limites do sucesso do empreendimento capitalista, do qual o Estado, em última instância depende.

Verificou-se acima que as crises do Estado e da democracia representativa e o avanço neoliberal são alguns dos fatores que incentivaram os processos de descentralização político-administrativa e as novas parcerias entre o Estado e a sociedade organizada. Esses mesmos fatores também serviram, discursiva e ideologicamente, para desqualificar a perspectiva estatal, política e pública da gestão ambiental e favorecer uma abordagem privatista e técnica dos problemas e da gestão ambiental. Esse movimento discursivo e, em alguns casos, pragmático, tem 
produzido discursos e propostas pautados na despolitização dos problemas e conflitos ambientais, na valorização de respostas técnicas e de inspiração privada no trato das questões ambientais e se expressa através de noções como as de: responsabilidade social, certificação ambiental (ISO 14.000), parcerias público-privadas, formação de consensos, ecoeficiência, autorregulação, governança, mecanismos de desenvolvimento limpo - MDL, consumo e mercados verdes ou de carbono, entre outras noções. Acselrad et al. (2006), analisando a produção discursiva sobre a gestão ambiental urbana, o desenvolvimento e a governabilidade após o ajuste neoliberal dos anos 1980 - que informa os novos modelos governativos -, mostram como ela é marcada pela desqualificação do Estado e da política, pela diluição dos conflitos sociais e ambientais, pela mercantilização das relações sociais e pela valorização do mercado e da inovação tecnológica como vias seguras e assépticas de promoção de crescimento e prosperidade. Nesse sentido, pondera que "os manuais que disseminam os novos formatos organizativos para enfrentar as contradições ambientais do desenvolvimento adotam modelos formais de adesão a uma 'consciência ambiental abstrata', desconectada dos conflitos ambientais concretos que desafiam aqueles atores sociais dispostos a democratizar o meio ambiente" (ACSELRAD et al., 2006, p. 23).

Pondera-se aqui que, ao defender a relevância da gestão ambiental estatal e pública não se pretende isentar as imperfeições da ação estatal. É necessário reconhecer suas fragilidades institucionais, a limitação de recursos destinados às políticas ambientais, a falta de continuidade das políticas, o sucateamento dos recursos humanos, a cultura burocrática e patrimonial que contamina as instituições públicas, a falta de integração entre os diversos setores de governo que se relacionam com o ambiente, além das próprias resistências que a gestão ambiental do Estado encontra na herança desenvolvimentista e tecnoburocrática (BURSZTYN, 1993). Contudo, reconhecer as debilidades do Estado não supõe seu desmantelamento ou retirada, mas, ao contrário, sua reestruturação e democratização, no sentido de torná-lo mais eficiente no uso dos recursos e no cumprimento das metas, mais consequente no planejamento e mais participativo politicamente. E por que o papel do Estado é relevante na sociedade capitalista? Porque sua ausência ou debilidade promove o império do mercado e suas consequências inevitáveis, quais sejam: mercantilização crescente das relações sociais, ampliação das desigualdades e da exclusão social, privatização do patrimônio público social e natural, restrições e retrocessos aos princípios de cidadania e equidade, aos direitos humanos e sociais, ampliação das externalidades ambientais e aprofundamento das assimetrias políticas, entre outras consequências. Isso porque a ação do mercado se orienta exclusivamente pela rentabilidade dos capitais investidos e pelo curto prazo e isso não garante respostas racionais aos problemas ambientais, equidade no trato da justiça social e respeito aos dilemas éticos frequentes na construção de uma sustentabilidade democrática. Refletindo sobre o papel do mercado na sociedade ocidental, Guimarães pondera:

O mercado nunca foi um princípio fundador da organização social ainda que, certamente condicione o comportamento econômico dos atores sociais enquanto produtores e consumidores [...] No presente século, ao contrário, é precisamente o Estado quem passa a ser considerado o contraponto para conter as forças cegas do mercado, que, abandonadas a si mesmas, seriam incapazes de realizar a felicidade humana [...] A economia de mercado que, na verdade, tem estado sempre conosco, ainda que com distintos matizes, é excelente geradora de riquezas, mas é também produtora de profundas assimetrias sociais (ver a respeito Guimarães, 1990). Por isso mesmo, o Estado (ou o nome que se queira dar à regulação pública, extramercado) não pode renunciar a sua responsabilidade em áreas chave como a educação, o desenvolvimento científico e tecnológico, a preservação do meio ambiente e do patrimônio biogenético e transferi-las ao mercado (GUIMARÃES, 1998, p. 8).

Tendo analisado os principais obstáculos que afetam o desenvolvimento das políticas e da gestão ambiental no Brasil nas décadas recentes, passamos a considerar algumas contradições desse mesmo processo que ajudam a compor a crítica do problema em foco e a construir alternativas democráticas para sua superação.

\subsection{Focalizando as contradições das políticas ambientais implementadas}

A descentralização política da gestão ambiental no Brasil, iniciada em 1981, com a instituição da Política Nacional de Meio Ambiente - PNMA - e fortalecida pela Constituição de 1988, tem sido discutida por diversos analistas, embora muitas vezes por um viés parcial que faz 
o elogio da descentralização sem identificar os motivos e problemas que estão em sua origem e desenvolvimento. Em primeiro lugar, deve-se reconhecer as inegáveis virtudes das iniciativas descentralizantes, por seu caráter democrático e promotor da participação social, mas existem aspectos nesse processo que merecem ser discutidos com maior atenção. Quando se considera em conjunto o processo de emergência de discursos e práticas de descentralização no Brasil, observa-se que ele também expressa a crise fiscal experimentada pelo Estado brasileiro, a partir de 1980, e a crise da democracia representativa visibilizada pelo contraste com a emergência dos novos movimentos sociais, ao longo da redemocratização pós-1985. Ou seja, a tendência à descentralização não decorre apenas da ampliação da democracia, mas também da incapacidade do Estado para atender as crescentes demandas sociais. Assim, ao menos em parte, a descentralização foi motivada pela necessidade de o Estado transferir encargos e responsabilidades que já não conseguia administrar. Com a descentralização, tanto se transfere atribuições às outras esferas da administração pública, no caso, estados e municípios; quanto a outras esferas da sociedade através de parcerias com organizações não governamentais - ONGs - e empresas. Dessa situação, resultam alguns problemas, como: a) se a transferência de atribuições para estados e municípios não for acompanhada por recursos e meios de implementação equivalentes, ter-seá uma prestação de serviços insatisfatória, no caso, políticas ambientais que não cumprem os objetivos desejados; b) ao transferir poderes e encargos a entes privados, altera-se o sentido de direitos públicos, que podem assumir uma nova feição de assistência voluntária ou de caridade privada; c) ao transferir as disputas ambientais para o âmbito local, corre-se o risco de ampliar a assimetria política entre os atores em conflito, devido ao maior poder relativo das oligarquias validarem seus interesses nesses contextos locais.

Ainda no âmbito da descentralização, a qualidade da participação exercida nos conselhos e fóruns criados como novos espaços públicos de participação social é bastante debatida e questionada. As críticas indagam, sobretudo, pela autenticidade e equidade da participação praticada, porque argumentam que, muitas vezes, a participação exercida é mais consultiva que deliberativa; que esse espaço participativo não existe em instâncias importantes ${ }^{2}$ ou que a sociedade civil participa, outras vezes, de modo minoritário; que a participação não se efetiva verdadeiramente devido à assimetria de conhecimento técnico entre os atores sociais em conflito e à manipulação política decorrente dessa assimetria de poder, por diversos meios, pelos grupos, política e economicamente dominantes, em especial quando se defrontam com comunidades tradicionais de baixa escolaridade e níveis inferiores de status social e de representação política. $\mathrm{E}$, em todos esses casos, a suspeita que emerge no debate é a de que uma participação espúria sempre acaba funcionando como um reforço na legitimação dos interesses já dominantes (CAMARGO et al., 2004; ACSELRAD, 2009).

Outro ponto controverso relacionado à gestão ambiental governamental se expressa através das "meias conquistas ambientais", frequentemente associadas ao contexto das unidades de conservação quando, por exemplo, o governo anuncia a criação de novas unidades de conservação e a ampliação da área total preservada, sem, contudo, oferecer condições reais de geri-las adequadamente através de planos de manejo e de gestão.

A incorporação da noção de desenvolvimento sustentável ao debate e exercício da política e da gestão ambiental no Brasil é mais um aspecto polêmico nesse processo de institucionalização das políticas e da gestão ambiental no Brasil. Para alguns analistas, ela representa o marco da maturidade desse processo, a conquista decisiva de um novo patamar ou paradigma de desenvolvimento no processo de superação dos problemas ambientais. Isso aparece, por exemplo, em Camargo et al. (2004, p. 44), quando afirmam: "É possível afirmar que o maior ganho da última década foi o reconhecimento de que as soluções para os problemas ambientais reside na noção de 'desenvolvimento sustentável' [...]”. Outros analistas, com os quais me alinho, reconhecem a importância e as inovações advindas desse debate, mas tendem a relativizar o otimismo com relação ao desenvolvimento sustentável, por considerarem essa noção repleta de ambiguidades e contradições que não a credenciam ao papel de referencial paradigmático no equacionamento dos conflitos ambientais. Ou seja, o debate sobre o desenvolvimento sustentável precisa ser cobrado a responder questões sobre sua viabilidade, objetivos políticos e éticos. Explicitar, por exemplo, questões como: O que sustentar? A economia, o ambiente ou a sociedade? Para

\footnotetext{
${ }^{2}$ CAMARGO et al., num trabalho de 2004, mencionam a ausência da sociedade civil na Comissão Técnica de Biossegurança - CTNBio - e na participação do governo brasileiro nas negociações do Protocolo de Kyoto.
} 
quem sustentar? Para alguns ou para todos os cidadãos? Como sustentar? Por uma via democrática ou autoritária? Ou ainda, com ênfase no mercado, no Estado ou na sociedade civil? Essas são algumas das perguntas mínimas indispensáveis à negociação social sobre os modelos de desenvolvimento que envolvem questões políticas, éticoculturais e estratégicas e implicam, portanto, na escolha de rumos sociais mais conservadores ou transformadores. Assim, de uma perspectiva construtiva, porém cautelosa, opta-se considerar a instituição e a hegemonia do discurso de desenvolvimento sustentável como o começo, a abertura de um novo ciclo de debates e não seu fim (LIMA, 2003; LEFF, 2001; PORTO-GONÇALVES, 2004).

Cunha e Coelho (2008), por exemplo, analisando a emergência do paradigma do desenvolvimento sustentável, constatam uma disputa interna ao debate entre visões filosóficas contrastantes e a constituição de uma concepção hegemônica de desenvolvimento sustentável de caráter instrumental. Os autores identificam, por um lado, uma visão ecocêntrica fundada em uma compreensão complexa do planeta Terra e na necessidade de mudanças radicais dos padrões ético e político capazes de transformar a base produtiva da sociedade ocidental. Caracterizam, por outro lado, a abordagem instrumental como aquela que defende a conservação por seu valor econômico, o mercado e a gestão dos recursos como instrumentos eficientes de promoção do desenvolvimento e a ideologia do progresso como fundamento filosófico da sociedade desejada.

A percepção geral que fica do debate acima é a de que o processo de institucionalização das políticas ambientais no Brasil avançou relativamente; de uma forma tortuosa, entretanto, vacilante e contraditória. Suas motivações, objetivos e instrumentos se construíram sob o signo da ambivalência e do pragmatismo econômico e, por conseguinte, não poderia apresentar hoje resultados mais consistentes e eficazes do ponto de vista socioambiental.

Tavolaro (1999) e Ferreira (1998) ilustram essa debilidade quando sugerem que, historicamente, a questão ambiental foi internalizada pelos diversos governos brasileiros por caminhos um tanto quanto artificiais. Ponderam, por exemplo, que a Secretaria Especial do Meio Ambiente SEMA - foi criada em 1973, em grande medida, como resposta do governo brasileiro à repercussão negativa na comunidade internacional - e pressões decorrentes da posição do Brasil na Conferência de Estocolmo em 1972, como demonstrou-se acima. A criação do Instituto Brasileiro de Meio Ambiente e dos Recursos Naturais
Renováveis - IBAMA, em 1989, pelo governo Sarney, segundo os autores, sofreu influência relativa do impacto exorbitante das queimadas na Amazônia nos dois anos anteriores, no contexto do debate mundial sobre as mudanças climáticas. Segundo Ferreira (1998), na gestão seguinte, a necessidade do governo Collor conquistar a confiança dos países desenvolvidos para financiar seu programa econômico também pesou na criação do Ministério do Meio Ambiente - MMA - e no protagonismo do Brasil na organização da Conferência do Rio em 1992. Argumentam, assim, que o processo de internalização da questão ambiental nas políticas de Estado no Brasil não obedeceu a uma motivação orgânica e endógena, mas a um processo gradual de constituição marcado por pressões externas dos países centrais e organismos internacionais, embora as pressões internas dos movimentos socioambientais também tenham funcionado em um plano secundário.

Feitas as análises de alguns dos principais limites e contradições do processo de institucionalização das políticas ambientais no Brasil, seguem-se as considerações finais.

\section{Considerações finais}

Embora de forma resumida, o artigo discutiu o processo recente de institucionalização das políticas ambientais no Brasil revisando a literatura da área à luz da Ecologia Política. A análise constatou a ocorrência de avanços institucionais e legais significativos que, contudo, não foram suficientes para conter a degradação ambiental no país e para instituir um processo de desenvolvimento social de perfil democrático, capaz de distribuir com equidade os benefícios materiais do crescimento econômico, a capacidade cidadã de participar na decisão dos rumos do desenvolvimento do conjunto da sociedade e os riscos ambientais advindos do próprio crescimento. A sociedade brasileira, não obstante sua grande disponibilidade de recursos econômicos e ambientais, manteve elevados os níveis de desigualdade social; não conseguiu ainda universalizar os direitos básicos que configuram uma cidadania plena e nem proteger as camadas mais pobres da população dos riscos e impactos decorrentes da degradação ambiental.

Ao considerar o diagnóstico esboçado acima, de que a política ambiental brasileira padece: de falta de vontade e prioridade política; de fragmentação intersetorial; de participação legítima; de incoerência entre leis e práticas e de ambiguidade estatal frente aos interesses privados, 
pode-se vislumbrar a magnitude e a complexidade dos desafios abertos. Como fazer para consolidar conquistas ambientais incorporando uma perspectiva de planejamento e de ação política complexas; uma postura política afirmativa e democrática diante dos problemas ambientais e para fortalecer uma concepção pública e política da gestão ambiental que valoriza a esfera pública e o papel Estado?

Como se vê, são múltiplos e amplos os desafios a trilhar. Desafios complexos que não se constroem

\section{Referências}

ACSELRAD, H. Cidadania e meio ambiente. In: ACSELRAD, H. (Org.). Meio ambiente e democracia. Rio de Janeiro: IBASE, 1992.

Políticas ambientais e construção democrática. In: VIANA, G.; SILVA, M. (Orgs.). O desafio da sustentabilidade: um debate socioambiental no Brasil. São Paulo: Editora Fundação Perseu Abramo, 2001.

; MELLO, C.; BEZERRA, G. (Orgs.). Cidade, ambiente e politica: problematizando a Agenda 21 local. Rio de Janeiro: Garamond, 2006. 132p.

2009.

O que é justiça ambiental. Rio de Janeiro: Garamond,

ALPHANDÈRY, P.; DUPONT, Y. O equívoco ecológico: riscos políticos da inconsequência. São Paulo: Brasiliense, 1992.

BARBIERI, J. C. Políticas públicas ambientais. In: BARBIERI, J. C. Gestão ambiental empresarial. São Paulo: Saraiva, 2006.

BeRGAMINI, R. Perfil das Despesas da União - Fonte $M F$ : de Janeiro de 2003 até Agosto de 2010. Disponível em: $<$ http://ricardobergamini.com.br/blog/?p=291> Acesso em: 19 nov. 2010

BERNARDO, M. Políticas públicas e sociedade civil. In: BURSZTYN, M. (Org.). A difícil sustentabilidade: política energética e conflitos ambientais. Rio de Janeiro: Garamond, 2001.

BURSZTYN, M. Para pensar o desenvolvimento sustentável. São Paulo: Brasiliense, 1993.

CAMARGO, A. et al. (Orgs.). Meio ambiente Brasil: avanços e obstáculos pós-Rio-92. Rio de Janeiro: FGV, 2004.

CASTORIADIS, C. Da ecologia à autonomia. São Paulo: Brasiliense, 1981 rapidamente, mas se maturam no exercício e no diálogo democrático. Nesse processo de construção de uma democracia ambiental, talvez os maiores obstáculos sejam os saberes reducionistas, os imperativos hegemônicos do mercado, o pragmatismo tecnicista e as estratégias discursivas do conservadorismo dinâmico que advogam reformas de superfície para garantir que tudo permaneça como está.

CUNHA, L. H.; COELHO, M. C. Política e gestão ambiental. In: CUNHA, S.; GUERRA, A. J. A questão ambiental: diferentes abordagens. Rio de Janeiro: Bertrand Brasil, 2008.

DIAS, G. F. Educação ambiental, princípios e práticas. São Paulo: Gaia, 1993.

DIEGUES, A. C. Desenvolvimento sustentável ou sociedades sustentáveis: da crítica dos modelos aos novos paradigmas. São Paulo em Perspectiva, São Paulo, v. 6, n. 1-2, p. 22-29, jan./jun. 1992.

. A globalização da proteção da natureza: o papel das grandes ONGs transnacionais e da ciência. In: DUPAS, G. Meio ambiente e crescimento econômico: tensões estruturais. São Paulo: Ed. UNESP, 2008.

DUPAS, G. Meio ambiente e crescimento econômico: tensões estruturais. São Paulo: Ed. UNESP, 2008.

DUPUY, J. P. Introdução à crítica da ecologia política. Rio de Janeiro: Civilização Brasileira, 1980.

FERREIRA, L. da C. A questão ambiental: sustentabilidade e políticas públicas no Brasil. São Paulo: Boitempo, 1998.

GORZ, A. Ecologie et politique. Paris: Galilée, 1975.

GUIMARÃES, R. P. Modernidad, medio ambiente y etica: um nuevo paradigma de desarrollo. Ambiente \& Sociedade, Campinas: NEPAM/UNICAMP, ano I, n. 2, p. 5-24, 1998.

HANNIGAN, J. Sociologia ambiental. Petrópolis: Vozes, 2009.

LEFF, E. Saber ambiental: sustentabilidade, racionalidade, complexidade, poder. Petrópolis: Vozes, 2001.

LIMA, G. F. da C. O discurso da sustentabilidade e suas implicações para a educação. Ambiente \& Sociedade, Campinas: NEPAM/UNICAMP, v. 6, n. 2, p. 99-119, jul.-dez. 2003. 
LIPIETZ, A. A ecologia política: solução para a crise da instância política? In: ALIMONDA, H. (Ed.). Ecologia política. Buenos Aires: CLACSO, 2002.

LITTLE, P. E. (Org.). Politicas ambientais no Brasil. São Paulo: Peirópolis, 2003.

LOUREIRO, C. F. B. O movimento ambientalista e o pensamento crítico: uma abordagem política. Rio de Janeiro: Quartet, 2003.

LÜCHMANN, L. H. H. Possibilidades e limites da democracia deliberativa: a experiência do orçamento participativo de Porto Alegre. Tese (Doutorado em Ciências Sociais) - Instituto de Filosofia e Ciências Humanas, UNICAMP. 215 f. Campinas, 2002.

MAGLIO, I. C. A descentralização da gestão ambiental no Brasil: o papel dos órgãos estaduais e as relações com o poder local, 1990/1999. Dissertação (Mestrado em Saúde Pública) - Faculdade de Saúde Pública, USP. 283 f. São Paulo, 2000.

MAIMON, D. Política ambiental no Brasil. In: MAIMON, D. (Coord.). Ecologia e desenvolvimento. Rio de Janeiro: APED, p. 59-76, 1992.

MARCUSE, H. A ideologia da sociedade industrial. Rio de Janeiro: Zahar, 1969.

MONOSOWSKI, E. Políticas ambientais e desenvolvimento no Brasil. Cadernos FUNDAP, São Paulo, ano 9, n. 16, p. 15-24, jun. 1989.

MORIN, E. (Org.). O problema epistemológico da complexidade. Portugal: Publicações Europa-América, 1996.
MOSCOVICI, S. Natureza: para pensar a ecologia. Rio de Janeiro: Mauad, 2007.

PÁDUA, J. A. O nascimento da política verde no Brasil: fatores exógenos e endógenos. In: LEIS, H. R. (Org.). Ecologia e política mundial. Rio de Janeiro/Petrópolis: Fase/Vozes, 1991.

Um sopro de destruição: pensamento político e crítica ambiental no Brasil escravista (1786-1888). Rio de Janeiro: Jorge Zahar Editor, 2002.

PORTO-GONÇALVES, C. W. O desafio ambiental. Rio de Janeiro: Record, 2004.

POULANTZAS, N. Political power and social classes. Londres: New Left Books, 1973.

QUINTAS, José Silva. Introdução à gestão ambiental pública. Brasília: IBAMA, 2006.

SCARDUA, F. P. Governabilidade e descentralização da gestão ambiental no Brasil. Tese (Doutorado em Desenvolvimento Sustentável) - Centro de Desenvolvimento Sustentável, UnB. 253 f. Brasília, 2003.

SCHNAIBERG, A. The environment: from surplus to scarcity. Nova York: Oxford University Press, 1980.

TAVOLARO, S. A questão ambiental: sustentabilidade e políticas públicas no Brasil. Resenha. Ambiente \& Sociedade, Campinas, n. 5, july/dec. 1999. Disponível em: <http://www.scielo. br/scielo.php?pid=S1414-753X1999000200017\&script=sci arttext>. Acesso em: 05 dez. 2010.

Recebido em março de 2011.

Aceito em abril de 2011.

Publicado em junho de 2011. 